\title{
Concomitant coronary artery revascularization to allow successful lung transplantation in selected patients with coronary artery disease
}

\author{
Richard Lee, MD, Bryan F. Meyers, MD, Thoralf M. Sundt, MD, Elbert P. Trulock, MD, and G. Alexander Patterson, MD, \\ St Louis, Mo
}

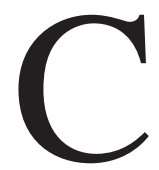

oronary artery disease has previously been considered an absolute contraindication to lung transplantation. Because of the scarcity of lung donors and a desire for the best organ utilization, patients with coronary artery disease were previously considered a prohibitive surgical risk. In addition, the potential adverse impact of coronary artery disease on the midterm survival after lung transplantation has excluded these patients from consideration for transplantation. However, several risk factors common to both end-stage lung and cardiac disease, most notably cigarette smoking and obesity, lead to a substantial incidence of coronary artery disease in potential lung recipients. ${ }^{1}$ Descriptions of successful coronary artery bypass before ${ }^{2}$ and after $^{3}$ lung transplantation have led some groups to perform coronary artery bypass at the time of lung transplantation with the assistance of cardiopulmonary bypass in a small number of highly selected patients. ${ }^{4,5}$ Recently, a case of combined coronary artery bypass and bilateral lung transplantation with off-pump techniques has been described. ${ }^{6}$ Here we describe 4 cases of combined lung transplantation and coronary bypass grafting: 2 with the assistance of cardiopulmonary bypass and 2 without.

\section{Clinical Summaries}

PATIENT 1. A 54-year-old man with a 22-pack-y history of smoking had end-stage lung disease from idiopathic pulmonary fibrosis. Preoperative cardiac catheterization revealed an $80 \%$ mid circumflex lesion but normal left ventricular function. An attempt at angioplasty was unsuccessful. After 2 years on the waiting list and substantial weight loss, the patient underwent right single-lung transplantation and coronary artery bypass to the first and second obtuse marginal branches of the circumflex coronary artery. The procedure was performed under cardiopulmonary bypass through a median sternotomy with a single sequential saphenous vein graft, with the proximal anastomosis at the aorta. The coronary artery bypass was performed first under tepid cardioplegia. The right lung was transplanted afterward. The patient did well after the operation for 6 months, when he was hospitalized and treated for an episode

\footnotetext{
From the Division of Cardiothoracic Surgery, Washington University, St Louis, Mo.

Received for publication Nov 27, 2001; accepted for publication March 25, 2002.

Address for reprints: G. Alexander Patterson, MD, One Barnes-Jewish Hospital Plaza, Suite 3108, Queeny Tower, St Louis, MO 63110 (E-mail: pattersona@msnotes.wustl.edu).

J Thorac Cardiovasc Surg 2002;124:1250-1

Copyright $\odot 2002$ by The American Association for Thoracic Surgery $0022-5223 / 2002 \$ 35.00+0 \quad \mathbf{1 2 / 5 4 / 1 2 5 6 5 1}$

doi: $10.1067 / \mathrm{mtc} .2002 .125651$
}

of acute rejection. Subsequently, pneumonia developed in the native lung, and he was treated for aspergillosis. Despite appropriate treatment, the patient died of chronic rejection 8 months after transplantation.

PATIENT 2. A 58-year-old man with a 30-pack-y smoking history, diabetes mellitus, hypertension, and hypercholesterolemia had end-stage lung disease from chronic obstructive pulmonary disease. Preoperative cardiac catheterization revealed a $70 \%$ lesion in his proximal left anterior descending coronary artery but normal right and left ventricular ejection fractions. During his 2-year period on the waiting list, he required multiple hospital admissions for respiratory failure. On hospital day 25 of one of these admissions, bilateral lung transplantation and coronary artery bypass grafting were performed through a sternotomy under cardiopulmonary bypass. The left anterior descending coronary artery was bypassed with a saphenous vein from the aorta under tepid cardioplegia. The lungs were then sequentially implanted. The patient's postoperative course was complicated by prolonged ventilation of 11 days and recurrent atrial fibrillation. Because of some lateral wall ischemic changes and a troponin of $1.6 \mathrm{ng} / \mathrm{mL}$, cardiac catheterization was performed 1 month after the operation. The vein graft was patent. The patient was discharged on hospital day 32. During the ensuing 17 months, the patient has remained in good health.

PATIENT 3. A 55-year-old man with end-stage chronic obstructive pulmonary disease and a 50-pack-y smoking history was referred for transplant consideration. A preoperative computed tomographic scan of the chest was remarkable for severe bilateral emphysema and coronary calcifications. Preoperative cardiac catheterization revealed an $80 \%$ circumflex stenosis and normal left ventricular function. After 26 months on the waiting list and substantial weight loss, the patient underwent bilateral sequential lung transplantation and single-vessel coronary artery bypass without cardiopulmonary bypass. A left pneumonectomy was performed through a left thoracotomy with excision of the sixth rib. The saphenous vein graft was placed from the descending aorta to the second obtuse marginal branch of the circumflex coronary artery. The proximal coronary anastomosis was performed with a partial occlusion aortic clamp. The distal anastomosis was performed with the assistance of the Medtronic octopus stabilizer (Medtronic, Inc, Minneapolis, Minn). The donor left lung was then implanted. Next, a right lung transplantation was performed through a right anterolateral fourth interspace thoracotomy. The patient's postoperative course was uncomplicated, and he was discharged on postoperative day 9. Two weeks after transplantation, the patient had an episode of acute rejection. He has done well during the ensuing 17 months, although a recent $10 \%$ decline in lung function may suggest the development of early chronic rejection. 
PATIENT 4. A 48-year-old man with a 70-pack-y history of smoking had end-stage lung disease from chronic obstructive pulmonary disease. He had a history of coronary artery disease with a previous stent in his left anterior descending artery and a $100 \%$-occluded right coronary artery. His history was also significant for several episodes of nonsustained ventricular tachycardia. Preoperative cardiac catheterization confirmed a patent left anterior descending coronary artery stent, an occluded right coronary artery, and normal left ventricular function. After 16 months on the waiting list, the patient underwent bilateral lung transplantation and single-vessel coronary artery bypass without cardiopulmonary bypass. The right coronary artery was bypassed from the ascending aorta to the posterior descending artery with a saphenous vein graft through a clamshell incision. The proximal coronary anastomosis was performed with a partial aortic occlusion clamp. The distal anastomosis was performed with the assistance of the Medtronic octopus stabilizer. This was followed by sequential right and left lung transplantation. The patient's hospital course was uncomplicated, and he was discharged on postoperative day 10. Six months after transplantation, he remains well.

\section{Discussion}

The presence of coronary artery disease has previously been considered a contraindication to lung transplantation. Because the median survival after lung transplantation is 60 to 72 months, a coronary artery bypass graft should last for the duration of a patient's life after lung transplantation. Therefore excluding all patients with coronary artery disease from lung transplantation may not be appropriate. Although we have only used vein as a conduit material in our series, there may be a role for arterial revascularization, especially as the life expectancy of lung transplant recipients continues to increase.

Patients with multivessel disease or left ventricular dysfunction were not considered suitable candidates to undergo lung transplantation. Only patients with normal ventricular function were listed at our institution. None of our patients have had postoperative complications related to their coronary disease to date; thus the addition of a single-vessel coronary artery bypass does not appear to have had a negative clinical impact. The patients who underwent combined operations without cardiopulmonary bypass had hospital and intensive care unit (ICU) stays comparable to those of patients without coronary interventions. Hospital stays were 9 and 10 days when the procedure was done without cardiopulmonary bypass and 14 and 32 days when bypass was used. Similarly, the ICU stays were 2 days for the patients without cardiopulmonary bypass and 2 and 17 days for the patients for whom bypass was used. In our program, lung transplantation for emphysema is usually conducted without cardiopulmonary bypass and patients typically remain in the ICU for 2 days, with a median stay of 12 days.

Our findings are corroborated by several other reports. A total of 9 patients in two other reported series have undergone concomitant lung transplantation and coronary artery bypass on cardiopulmonary bypass. ${ }^{4,5}$ All patients had single-vessel disease, except for 1 who received three bypass grafts. One additional patient underwent two-vessel bypass and bilateral lung transplantation without the assistance of cardiopulmonary bypass. ${ }^{6}$ All patients were discharged from the hospital. There were no deaths from coronary disease. The survival ranged from 75 days to greater than 56 months. The hospital stays varied widely. In the other series, ${ }^{4-6}$ however, the patients with combined procedures had longer ICU and hospital stays than did patients without coronary intervention.

Too few patients have received combined lung transplants and coronary artery bypass procedures to draw any conclusions. However, it appears that the combined procedure can be safely performed in highly selected patients, with or without cardiopulmonary bypass. Limited coronary artery disease in otherwise good candidates may no longer be an absolute contraindication to lung transplantation.

\section{References}

1. Leibowitz DW, Caputo AL, Shapiro GC, Schulman LL, McGregor $\mathrm{CC}$, Di Tullio MR, et al. Coronary angiography in smokers undergoing evaluation for lung transplantation: is routine use justified? $J$ Heart Lung Transplant. 1994;13:701-3.

2. La Francesca S, Shennib H. Coronary artery revascularization followed by single-lung transplantation in a patient with combined end stage idiopathic pulmonary fibrosis and left main coronary artery stenosis. Texas Heart Inst J. 1995;22:189-91.

3. Salerno CT, Harrison BS, Hertz MI, Shumway SJ. Coronary artery bypass after single lung transplant: a case report. Clin Transplant. 1997;11:463-5.

4. Snell GI, Richardson M, Griffiths AP, Williams TJ, Esmore DS. Coronary artery disease in potential lung transplant recipients $>50$ years old. Chest. 1999;116:874-9.

5. Patel VS, Messier RH, Palmer SM, Davis RD. Coronary artery revascularization in eligible lung transplant recipients. J Heart Lung Transplant. 2001;20:223.

6. Khatchatourian G, Chevalley C, Spiliopoulos A, Licker M. Myocardial revascularization and bilateral lung transplantation without cardiopulmonary bypass. Eur J Cardiothorac Surg. 2001;20:1042-4. 